So, four decades later where did we get to? Daniels cites Levett as showing that only about 14\% of social workers held a qualification in 1969 (Daniels, 1973, p.47). In 1981 a larger study reported only $12 \%$ of social workers had a social work qualification (Rochford \& Robb, 1981). It is now very difficult to get any broad figures to compare, but we can assume that the overall percentage of qualified social workers is much higher, perhaps $60 \%$ (based on anecdotal information), but the majority would hold a diploma as their highest social work qualification. We currently have recognised programme at 16 institutions, in five universities, in two wananga and nine polytechnics.

So many programmes yet still at least a moderate shortage of qualified social workers and an aging workforce. Agencies are still employing unqualified workers.

Where will we be in $2047 ?$

\title{
References
}

Daniels, K. (1973). Social work education: A time of crisis. The New Zealand Social Worker: News and Opinions, 9(4), 43-55.

McLaughlin, K. (2007). Regulation and risk in social work: The General Social Care Council and the Social Care Register in context. British Journal of Social Work, 37(7), 1263-1277.

Nash, M., \& Munford, R. (2001). Unresolved struggles: Educating social workers in Aotearoa New Zealand. Social Work Education, 20(1), 21-34.

Ritchie, J.E. (1967). The relation of the university to the profession of social work. New Zealand Social Worker: News and Opinions, 3(2), 3-13.

Ritchie, J. (1992). Becoming bicultural. Wellington: Huia Publishers: Daphne Brasell Associates.

Ritchie, J., \& Ritchie, J. (1978). Growing up in New Zealand. Hornsby, NSW: Boston: George Allen and Unwin Australia.

Rochford, M. W., \& Robb, M. J. (1981). People in the social services. Wellington: New Zealand Social Work Training Council.

\section{The relation of the university to the profession of social work}

\author{
James E. Ritchie
}

At the risk of seeming academic and pedantic I would like to attempt at the outset to clarify (in my own mind at least), just what is meant by membership in a profession. I want to do this in the first instance because many people have the erroneous idea that for a profession to be established as such and for a person to claim professional status all that is needed is some qualification from a university or professional college. This attitude has led to a continuing and increasing demand on universities, here as elsewhere, to accommodate or adapt to their courses in ways which are not always in the best interests of university education or necessarily likely to achieve the objects of the profession. In some cases the universities have acted almost without consultation with the relevant professional association, in other cases rejected quite proper professional demands.

Within the last few years we have seen management, nursing, optometry, correctional clinical and educational psychology and a number of other cases for professional training 
put to and considered by university governing bodies, or government or other policy making and deliberative agencies. Within the universities themselves there has been considerable redefinition and reappraisal of the proper function of a university, and I think it would be fair to say that in this process the public or national factor, that is servicing professional training needs as they exist in the country, has sometimes been given greater deliberative weight than is either necessary or desirable. It is therefore not unfortunate to see that this association has been forced to an autonomous and independent line, the consequence of which should be greater clarification of the kind of training which you feel those currently engaged in social work should be able to undertake. The maintenance of standards and of appropriate means of further training are an essential part of professional organisation. Your deliberation on this matter is evidence, therefore, that your Association already has professional standing and responsibility, that you have been not only willing to set out your requirements in explicit terms but that someone such as myself looking at the proposals which were placed by your Association before the Director-General of Education can recognise that these curricula, course and practical requirements, constitute a reasonable and thoroughly worthwhile proposal for in-service training. They are not, however, as we all recognise, a sufficient programme for training in general since they are not intended to equip an individual before entry to the profession, nor to provide for the continuous re-training which modern professions require.

To be a member of a profession implies, first of all, that one's conduct is governed by an agreed system of ethics. It implies a sense of vocation in terms of the aims of the profession. It implies that this vocation is not merely switched on during working hours and switched off after the time clock is punched, but that one's entire life is shaped around one's vocational dedication to the objects of the profession. It implies also that the individual concerned has been willing to prepare to the standard required for professional membership and to do so often at considerable personal cost. It is not a necessary part of professional status that one should accept a lower earning power than those who work outside the professions- though in New Zealand it may often seem to work out that way-but in almost every profession there is an extended training period during which the individual must defer high earnings in order to acquire the skills of his professional craft. He must mature in the knowledge, skills, attitudes, and ethics of the profession and this process must necessarily take many years. But the core of a profession is that which it professes, namely, the application of some body of knowledge to some purpose which will further the social rather than personal good.

Within the occupational range, professions are different in kind from other sorts of employment. My butcher is an amiable chap who no doubt is trained for the job that he does and I would not deny that this job contributes to my personal good and presumably, therefore, to the social good, but this is not his central purpose. No doubt he had to spend some time learning his trade and during his apprenticeship defer the privilege of earning a high income in some other occupation, but the period is short and once ended the training is over. Since he seems a happy butcher he presumably had an inclination that led him to this trade rather than some other but it hardly constitutes a sense of vocation. In these things a trade and a profession are similar but different. What most sharply marks off the professional person are three core qualities of professional activity, namely, the ethical charter which all members of the profession accept, the absorption of the professional person in his job so that he is in a sense never off duty, and the fact that he is applying knowledge, not merely practising a skill and I include in this the research nature of knowledge which means in effect that training and learning can never stop for any professional person. 
These are the three aspects of professional activity which make training absolutely essential. My butcher has the ethical standards which prevail generally in our society and is not therefore a notably lawless, immoral, unscrupulous or untrustworthy person, nor is he notably the opposite of these things. His wife, his friends and other butchers would certainly think it strange if butchering became his pre-eminent priority in all aspects of his life. The knowledge which he requires to exercise his skill is defined by that skill. He is not called upon to have any interest in new knowledge, nor to advance knowledge, nor is he likely to find a situation arising in which some item of fact acquired years before suddenly becomes useful in a new context within the operations of his vocation. His training, therefore, gave him skills rather than knowledge, was directed to this end, and he is a good butcher. By becoming a good butcher, he did not become a different kind of person. But the person who intends to enter a profession, having acquired the ordinary socialisation which would lead any individual to the ordinary ethical, vocational and occupational standards which prevail in our society, must be resocialised. The professional person has had to go through a process of acquiring the attitudes as well as the knowledge and the practices of the profession and therefore must subject himself or herself to what is termed in the literature of social psychology, adult socialisation.

We don't know nearly enough about the process of adult socialisation and until we do there will always be arguments about how to design professional training programmes. Erving Goffman, in his book Asylums, examines some aspects of this process in relation to 'total' communities, such as, those who have accepted the monastic life, entered the army, or become members of a prison community, or patients within a mental hospital population. In these cases he draws attention to the depersonalisation which is part of the socialisation process, to the hazing and other egoalien and psychologically painful processes, whereby a person is persuaded, by the personal effort and cost that he must invest, that membership of the community is worthwhile. He then analyses the way in which the depersonalised individual is progressively taught by other members of the community how to act appropriately in the setting of that particular situation. And finally such novices are given some insignia of rank, put through some ceremony of initiation or given some set of privileges once they have achieved the conforming status of participating members. Goffman is not comparing these processes of adult socialisation merely to amuse, to be off-beat, or to be iconoclastic. He is setting up a model, albeit a limited one applicable in the first instance only to those institutions that he discusses and possibly only to some individuals within those institutions, so that we can recognise similar processes occurring in other institutions, and if need be, design better ways of producing loyalty and good conduct. Many of the features of his model have certainly crept into our educational and social structure at many points, the universities themselves being one, and the public service perhaps being another. At the most general level, Goffman's analysis has a very wide applicability. It is only a special case of the process of unlearning and relearning with an appropriate reward to stamp in the pattern.

When a professional body approaches an institution such as the university for assistance with its training programme, it is in effect, asking the university to take part in directing the process of adult socialisation towards specific ends, to assist in the unlearning-relearning-reward sequences. Universities are traditionally suspicious of other people's purposes, and this apprehension is proper but often over-great. 
The approach may be made for many reasons, not all of which can be recognised by a university as appropriate to its own purposes. But it is nevertheless right, overall, that the approach to the university should be made and should be pursued, for the university itself is a major and effective agency for adult socialisation; it is very familiar with the unlearning-relearning-reward business. Perhaps the accent has been rather too much on the unlearning-relearning part with university academics expressing little interest in the reward. I sometimes feel that they, having invented for themselves their own perpetuating system of examination and degree granting as an artificial reward system, and having persisted for centuries in the delusion that knowledge should be its own reward, have obscured the real rewards that spur students on. The real rewards that have probably motivated students throughout the centuries that universities have been in existence, have been either the entry which a university training gives to a profession, or the entry to the profession of university life which has its own particular professional satisfactions. Since this last has often loomed large in the minds of those who teach in universities, the distinguishing characteristics of the university as a professional environment itself have been its own curious system of ethics, its own dedication to its own concerns (the ivory tower no less) and its elevation of knowledge as the superior social good. The New Zealand university in particular has at certain times and in certain places been considerably influenced by its own professional nature, giving rise to a number of undesirable consequences. The detachment of the university from matters of national or public, or social, concern is far less a danger than most laymen think, indeed in many ways its detachment is under continual pressure and attack. But there is always a body of academics to argue in defence of it. Perhaps the most damaging feature of this professionalism has been the effect which it has had on the priority set within the overall aims of a university. These are: the transmission of knowledge through teaching, the application of knowledge through professional training and finally the acquisition of new knowledge through research. I place them in this order because to do so reflects the prevailing nature of the university as it has developed in New Zealand. We have many teachers who do no research, but very few researchers who do no teaching. Because university funds must derive ultimately from the public purse, it is always easier to justify a programme of professional teaching, than to argue for some aspect of knowledge which has no ready application or apparent utilitarian purpose.

All this lies behind some of the difficulties which you have been experiencing in attempting to persuade the universities and others to accept what seem to you proper and justifiable training needs. I think it is essential that you should continue actively to assert the rightfulness of your assuming a professional role for those aspects of adult socialisation which your profession requires and which the university is ill-equipped to service and unwilling to handle but to insist that the university does what it is best able to do. In other words, your Association should concern itself actively and aggressively with the implementation of training programmes which are mainly directed at the ethical standards you wish your profession to maintain, with the maintenance of a proper sense of dedication and with the acquisition and development of professional skills within a professional setting. But I think it would be wrong for you to give up your expectation that the university must ultimately provide what it is best able to provide, viz., a good background training for undergraduates who may ultimately enter the profession, the research background which people in your profession must have available if you are to continue to develop your profession, the extension to your membership either through undergraduate, postgraduate or extension programmes, of the knowledge which university personnel have, an appropriate recognition 


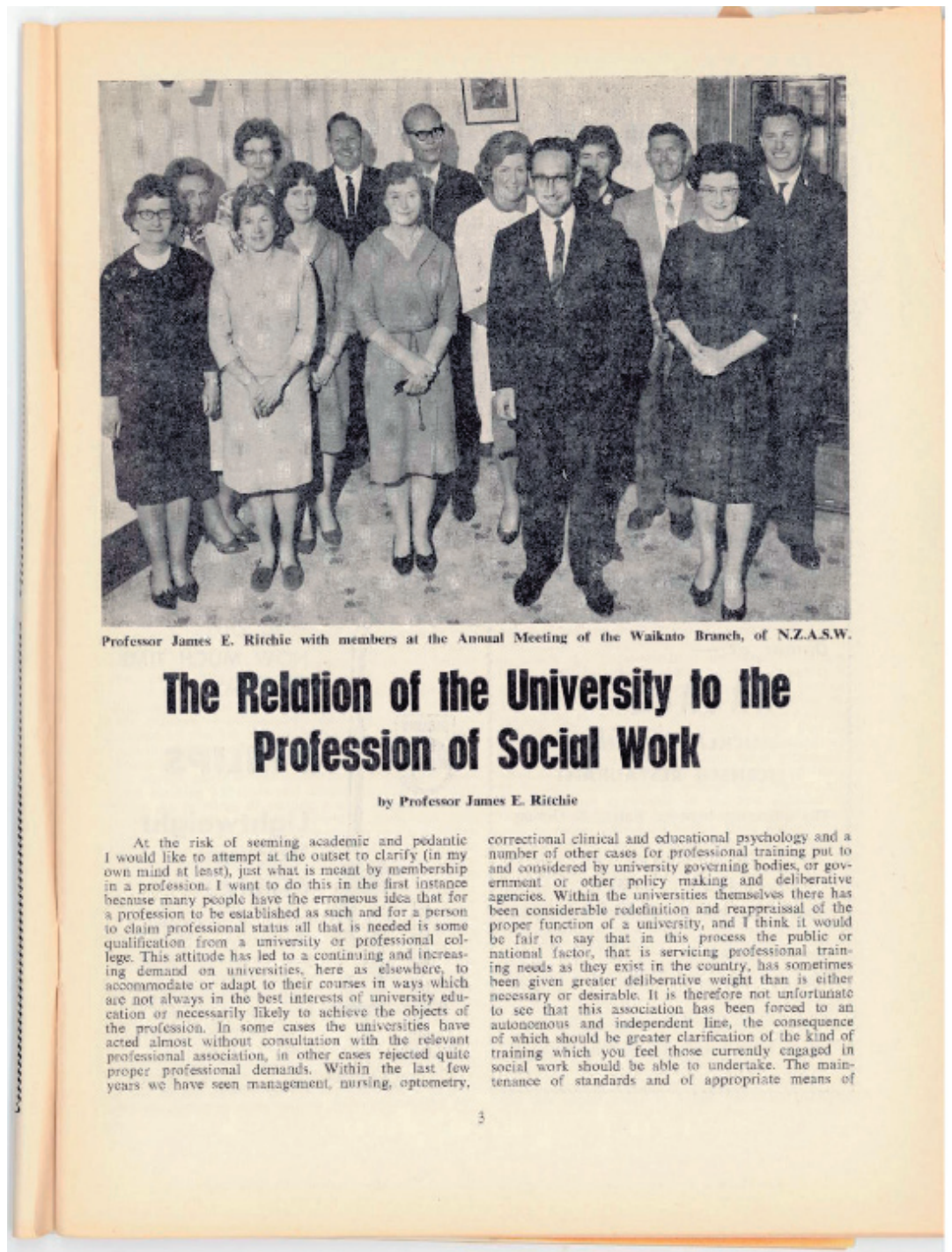

that your profession, along with others, has a claim on part of the undergraduates educated at the university, and on the teaching time of those within the university who have knowledge related to your profession.

Let me turn now to a quite different aspect of this general question. Your immediate proposals for certificate courses for your members are the product of your needs in the particular circumstances that pertain in New Zealand at the present time. Were you to be asked to suggest a curriculum for the training of social workers who might be employed in the year 2000 the proposals might be different. To a group as pragmatic and down-toearth as social workers are, such a suggestion may be greeted with acute alarm, for I know of no profession where idealism and realism are so intimately married. I do think, however, that your time perspective for any training proposals which you might be seeking to 
implement now, needs to be defined with a similar neat balance between needs existing now and those of the future. Let us turn then to the overall picture of social work needs as they are developing in New Zealand and the kinds of training appropriate for these. I will discuss this matter not in terms of statistics but the changing nature of the profession and the society it seeks to serve.

The traditional practice of social work has been dominated by Christianity, case work, and - let us be frank - conformity. Its basic principles were formulated during a time when class structure was very different from what it is now and volunteer social work a good deal more popular than is now the case. It is a phenomenon of urban industrial society and saturated with implications which derive from the assumption that society, particularly urban industrial society, retains within it stable social structures such as church and family which are relatively unchanging.

While Christianity remains one basis for the motivation which leads people to enter social work, it is not now the only basis, and it is doubtful whether it is an appropriate basis for operation in a society in which religious belief has become substantially nominalistic. As a basis for practice, Christianity will work for some social workers all the time, and perhaps for all social workers at some times and with some clients, though many will prefer not to use a religious basis for their practice, however religious they may be. Whether within or without the general Christian formulation, some generally acceptable basis for the ethics of the profession must be found and since not all members of the profession are, or need be, Christian, it must be outside the religious basis of the Christian ethics that the agreed territory must lie.

The emphasis on case work is similarly inadequate. Within what has come to be termed social psychiatry it is now recognised that the use of therapeutic groups, the establishment of therapeutic communities, family therapy and preventative psychiatry, all have more efficient payoff than individual therapy. I think we now recognise that though one may start with an individual problem, one must always finish by attacking some aspect of a social problem. We are still searching for the definition of what community means in an urban setting and while we search we must be prepared to deal with Watts, or Harlem or Porirua East. Furthermore, there is a strong call for trained social workers operating within the relatively impersonal operations of welfare administration, so that to the traditional categories, case work, group work and community work, one must add two other categories where social work skills are needed, those who administer welfare in any of its aspects and those who work within administrative agencies to reduce the characteristic 20th century tendency for such agencies to become impersonal. In this latter category I would certainly place those who are working within industry to evolve management procedures which may lessen the de-humanising impact of industrial technology. Such individuals may never see the client in the ordinary sense of the term.

The pressures towards conforming behaviour which social workers are called upon to exercise (with or without their knowledge or awareness), present one of the most acute problems within the profession, one which it shares to some degree with some other professions, the church or primary and secondary school teaching. It is very easy to call on social workers to assist in the promotion of individuality and social heterogeneity and to resist the pressures of middle class conformity but extraordinarily difficult for the individual social 
workers to see just how these aims can be achieved in the ordinary course of his or her duties; the more so where the client has learnt rather well the business of conforming to some deviant group, so that to transfer conformity to some more acceptable social mode seems the easiest and most efficient way of reducing both the personal distress of the client and the social disruption he or she may cause. I can offer no general answer to this problem. Nor can I see clearly where the increasing conformity pressures of our kind of society are likely to lead. All I can offer is the general conclusion of social science research that the range of human individuality being what it is, the greater the pressure to conformity the more likely it is that some members of the social group will demonstrate lawlessness and wilfully seek to be deviant. All that I can offer is considerable research examination of conformity processes, and their consequences both personally and socially. It is certainly more efficient to shift deviant group goals towards more acceptable objects but leave them deviant, than to disrupt the primary group satisfactions that they offer their members.

Social work is no longer something done by volunteers, the affluent few for the under-privileged many. But the affluent society is anything but free from the need for the ministrations of the profession. It is certainly more aware of the need, though reluctant to support genuine social welfare services. It may, in fact, be requiring proportionately more of them, and its problems certainly require greater subtlety, sophistication and skill from those who practise on its behalf the arts of social work. If one tries to look ahead to estimate the number of social workers that New Zealand will need over the next 50 years it is difficult to find any other basis than an extension of the present ratio of social workers per hundred thousand of population. However, since we would all acknowledge that the present provision for social workers is inadequate, I think that the arithmetic must be more complicated. You need to attract more qualified graduates to the profession and unless career possibilities can be spelled out in very definite numerical terms there is little hope of your getting them and training proposals must be correspondingly undertaken in a planning vacuum.

While New Zealand social work operates mainly in urban settings and while internal migration will increase the proportion of people in such settings, they differ very widely from the industrial situations in which social work had its beginnings and in which its foundations were laid. As a profession, I think you need to examine just what this means because the result of such an examination would have considerable effect on the kind of training programme which you would want to put into operation to equip social workers for the society which is just ahead.

Finally, in this admittedly outsider view of what your profession is about and where it is heading, let me state my views that your profession, like many others has had a considerable area of its foundation assumptions cut away by the realisation that the steady state theory of society is invalid. Whether it has always been so or whether we have reached a stage of urban social evolution that has produced a new kind of human society is not a matter which I would like to debate at this point. The facts I think clearly indicate that we must all adapt our professional programmes to a condition of continuous change in which some institutions may be forced into a temporary retrenchment of excessive stability, while others virtually disappear or become unrecognisable under the impact of modern mobility, scepticism, technology, knowledge and changing function. This and all the things which I have mentioned would seem to me to be part of the territory which must be traversed before 
the definition of what should be included in the professional studies part of any training curriculum can be satisfactorily arrived at.

Whatever direction and speed of development in social services may be it is quite clear that how future governments interpret the meaning of welfare in the New Zealand Welfare State is likely to affect the profession of social work in a vital way. So long as welfare policy remains substantially a matter of improving material conditions by housing, pension benefits and other economic aids, there will not be enough cash to put welfare in the wider sense on a proper basis. Having erected a welfare state we must now proceed to the second phase of servicing it with appropriate professionals. The New Zealand 'lurk' of setting up an untrained cadre of untrained people, giving to them a professional title, and then denying their rightful concern to establish their profession by appropriate training, a pattern all too often repeated in our recent history, cannot be allowed to go unchecked.

Let us look now at the provisions which are already available for the training of social workers in New Zealand.

The oldest, most traditional, and vitally necessary part of any professional training is the probationary, intern or apprenticeship phase - that part of training which each of you is able to give out of the store of knowledge, your dedication and your acceptance of the ethics of social work, to any young person with suitable vocation who comes under your direction. You should, I think, within your own Association be very much concerned with the improvement of the transmission of professional knowledge and skills through internship and placement. This you can do for yourselves by appropriate seminars and by frankly discussing amongst yourselves, as groups or individually, problems that may arise with recruits who are associated with you in your work. I would hope also that your agencies might find a role for undergraduate students. Not only those who have decided on a career in social work, but those who may not have decided on a career at all and who might be encouraged to think of this as one possible vocation at the end of their university studies, could benefit by a sort of 'pre-apprenticeship', if for no other reason than to dispel romantic illusions. Any extension of training is going to increase the supervision load of all your members very considerably and this is a professional responsibility which I am sure you welcome, however onerous it may be.

The second major training avenue is through short course in-service arrangements. These are undoubtedly valuable and are highly regarded. There is, however, a tendency, particularly within the state services, to accept the short course alternative as an adequate stop-gap and indeed, I believe, to over-value it. In-service courses can only draw on a tiny proportion of the relevant knowledge which is pertinent and available within universities. They have a tendency to focus narrowly on techniques. Over-reliance on them will not only impair your professional standing in relation to other professions but may in the long run impair your professional competence. Anyone in any profession needs regular opportunity to get away from the detail of doing things and get time to evaluate what he or she is doing and gain fresh perspective.

The School of Social Science in Wellington is the only attempt which has so far been made to set up a proper programme of full professional training. It gives one year less training than a primary school teacher receives: I make no other comparisons. Professional 
schools in the New Zealand university system have a strange and confused history. Some like the Otago Medical School are not only fully professional but also fulfil the functions of a university programme in general and have correspondingly been adequately funded and staffed. Others, like dentistry, began well below a satisfactory university level in both finance and staffing and have had to fight slowly and progressively up towards full recognition and status. Where there is more than one school competing for scarce resources within a particular university the stimulus and challenge has generally been beneficial. The School of Social Science at Victoria is the only special school within that university. At its inception it was specially funded and its intake was drawn from the ranks of the profession rather than from an undergraduate or graduate population. Its teachers often duplicate the knowledge available elsewhere in the University. As a school it does not have a dean but a Head of Department with professional status who must, now that special financial provision has been withdrawn, fight along with the ordinary academic departments without any guarantee that the special requirements of a special school will be met by special provision. From the outside, the School of Social Science (chiefly because of its limited intake) seems inevitably to have been forced in to the role of an institution for the creation of administrative elite for the profession, rather than an adequate source of sufficient trained recruits to obviate the necessity to take in untrained entrants to the profession.

From the inside, from Victoria, it has seemed a separate, even separatist part of the body of the university. Thus even were it to attract graduate students to take its diploma as a postgraduate qualification, their education for social work would have been singularly uncoordinated. In fact, its limited intake and the necessity that the experienced professional person from the field should be given the advantage of the diploma course, limits the number of graduates who could enter the school even if there were large numbers who wished to do so. Nevertheless, in what must have seemed at times to those involved an almost intolerable situation, the product of the School of Social Science has been uniformly good and its effect on the profession of social work equally salutary. I am sympathetic with the problems which the School has faced, is facing and I do not claim to know of them all or to understand them well. I believe that there are proposals for the designing of a co-ordinated undergraduate degree as an appropriate pre-requisite for further training in social work, at Victoria. The success of this would depend on a degree of inter-departmental co-operation and co-ordination which in the past Victoria has been singularly unable to demonstrate. If and when a second university school for the training of professional social workers is established, the following criteria should guide the decision as to where it should be located and how it should operate:

1. There should be due consultation with this Association in the planning at all stages.

2. The second school should aim to produce a product of different orientation and character from that produced by the existing school.

3. Evidence of (not promises of, or hopes for), co-ordination within the social sciences should be forthcoming.

4. The usual pattern of a general social sciences four-year undergraduate degree plus a two-year postgraduate course, plus at least one year of internship, should be followed.

5. The programme should be full-time.

6. In-service training should be substantially located at the school and administered by it and suitable staff allocations made to enable this to be done.

7. The staff-student ratio must be guaranteed to be and to remain more liberal than general university ratios. 
8. Provision should be made for a vigorous programme of research into social problems and especially into the practice of social work.

9. The school should be identified with some innovative programme, say of community health centres (including mental health) or some action research programme in which the inter-relation of social problems can be clearly seen.

10. Your Association should set ahead a date on which its membership criteria will be tightened to admit only graduates.

To close, let me make a few observations on the current proposals of this Association to establish a certificate in social work. This seems to me similar to the position which arose in accountancy where a professional society and the universities were in effect trying to provide much the same kind of training. The universities drew away from this situation by increasing the academic content and the university standing of accountancy courses and by requiring accountancy students to study general units in addition to their professional subjects.

Eventually this tendency reached the point where some universities were able to restructure their faculties of accountancy to meet more satisfactorily the subject groupings and the style of modern thinking concerning this professional area. At the same time the Society of Accountants indicated that they would like to desist from paralleling the accountancy courses run by the universities and reach, within a very short time, the point where they can require a university degree for membership of their Society. This minimal membership entrance requirement can then be supplemented by high level courses of a specialised nature run by the Society.

The process of evolving this pattern has been long and agonised. I would not wish to see your Association repeat it. If you were at this point to set a target date beyond which you would accept only graduates into the membership of your Association, not only would you strengthen your professional standing, but you would also show the universities that you mean business and that they must hasten to give proper consideration to the needs of the nation for trained social workers within undergraduate programmes. As an afterthought I might add that you would probably increase the rush of those who are not members of the Association to join with you before the axe falls. There may be special fields of social work where it might be difficult for some time to get adequate recruitment from graduate ranks, Maori welfare particularly comes to mind, but such problems can be overcome within a system of membership grades. The certificate your Association has proposed is certainly worth pursuing for its undoubted value to those who have not had the advantage of a university training and for whom it is now not a realistic objective. But it should not deflect your Association from the definition of an appropriate professional qualification for future membership to operate after a not-toodistant date and it should not permit the universities to escape their responsibility to service this professional need by a programme acceptable both professionally and academically.

University training will not guarantee good professional standards, but they probably are unobtainable by an Association such as yours without it. An undergraduate degree will never be enough on its own and must be viewed as one slice of bread in a sandwich, the other being postgraduate training and the meat being internship and in-service experience and training within the ordinary operations of the profession and its association.

In a phrase, I can sum up by saying that it is for you to set your training sights on what seem to you proper professional goals: the lower you set them the less you will achieve all round. 